\title{
Susceptibility of Pseudomonas aeruginosa isolated from urine to some antibiotics
}

\author{
H.Ali Salih M. Abdulbary A.S. Abdulrida \\ Coll. of Pharmacy / Univ. of Al- Kufa
}

\begin{abstract}
Pseudomonas aeruginosa is a member of genus Pseudomonas that it is Gram negative, glucose - nonfermenting aerobic rod, isolated from chronic UTI . It is resistant to high concentration of salts and dyes, weak antiseptics and commonly used antibiotics. Because of the increasing in drug - resistant of strains of $P$. aeruginosa especially that which isolated from UTI, this study was done among the patients attending hospitals in Al-Najaf city during January to December 2009 to maintain the susceptibility pattern of organism isolated from urine specimens. A total $72(100 \%)$ samples of $P$. aeruginosa were isolated from urine specimens of patients. The bacteria isolated were identified by colony morphology, microscopy and relevant biochemical tests. Antimicrobial sensitivity pattern was tested using standard guidelines. Almost all of the $P$. aeruginosa isolates were sensitive to Amikacin(100\%) , Norfloxacin(86\% ) Ciprofloxacin(83\%) \& Tobramycin(83\%) but highly resistant to Doxycycline.
\end{abstract}

Pseudomonas aeruginosa is a member of genus Pseudomonas which belong to the family pseudomonadadaceae. It's Gram - negative , glucose nonfermenting aerobic $\operatorname{rod}^{1}$, all strains are motile by means of a single polar flagellum, commonly found in soil and water. Pseudomonas aeruginosa resistant to high concentration of salts and dyes , weak antiseptics and commonly used antibiotics $^{2}$.Pseudomonas aeruginosa is an opportunistic human pathogen ${ }^{3}$. Although it is not generally considered as the causing of urinary tract infection several cases of UTI probably caused by Pseudomonas aeruginosa. It is isolated from chronic UTI especially with catheterization ${ }^{4}$. Most of Pseudomonas aeruginosa resistant to the antibiotics used in the treatment of UTI especially associated with those cases of hospital acquired infection mainly in immunocompromised

1.The study was conducted in the department of Microbiology, Kufa Pharmacy College during the period of January to December 2009.

2. Collection of samples : urine samples collected from patients come to hospitals in Al-Najaf city, the mid - stream urine patients ${ }^{5}$.Antimicrobial resistance is a natural widespread phenomenon ${ }^{6}$ and the resistance mechanisms can change and evolve as quickly as bacterial cells multiply $^{7}$. several studies have shown that humans were colonized with resistant clones of bacteria, even months after having received antibiotics ${ }^{8}$. The emergence of resistance in Pseudomonas aeruginosa limits therapeutic choices and is associated with increased rates of morbidity and mortality, higher costs and prolonged hospitalization relative to antibiotic - susceptible bacteria ${ }^{9}$. Pseudomonas aeruginosa has become an important hospital pathogen ${ }^{10}$, and we observed an increase in drug - resistant of strains of $P$. aeruginosa especially that which isolated from UTI. So, we decided to carry out a study to see UTI caused by $P$. aeruginosa and susceptibility pattern of organism isolated from urine specimens.

\section{Methods}

were collected from patients complaining from symptoms of UTI.

3.microbiological study : The urine samples have been direct microscopical examination to the feculence after centrifugation and leave the clear filtrate, thus to investigate about the 
microorganisms, epithelial cells, pus cells and blood cells ${ }^{11}$. Loop full of urine samples were cultured on the media MacConky agar, nutrient agar and blood agar base and the isolated organisms Pseudomonas aeruginosa were identified by colony morphology, microscopic

\section{Results}

$(100 \%)$ but the highly resistance of The susceptibility of isolated Pseudomonas Pseudomonas aeruginosa is to Doxycycline (100\%) table 1. examination and relevant biochemical tests $^{12}$.

4.Antimicrobial sensitivity test was done by disc diffusion method $^{13}$ against antibiotics including Ciprofloxacin, Nalidixic Acid, Doxycycline, Gentamycin, Amikacin, Tobramycin, Norfloxacin of standard strengths. aeruginosa from urine to antibiotics is shown in table1.The highly sensitive of Pseudomonas aeruginosa is to Amikacin

Table1 :Pseudomonas aeruginosa susceptibility ratio to antibiotics

\begin{tabular}{|c|c|c|c|c|}
\hline No. & $\begin{array}{c}\text { Antibiotic } \\
\text { name }\end{array}$ & $\begin{array}{c}\text { Antibiotic } \\
\text { symbol }\end{array}$ & $\begin{array}{c}\text { P. aeruginosa } \\
\text { susceptibility }\end{array}$ & $\begin{array}{c}\text { The ratio according to total } \\
\text { sample number (72) }\end{array}$ \\
\hline 1 & Ciprofloxacin & Cip & S & $83 \%(60)$ \\
\hline 2 & Norfloxacin & Nor & S & $86 \%(62)$ \\
\hline 3 & Tobramycin & Tob & S & $83 \%(60)$ \\
\hline 4 & Amikacin & Ak & S & $100 \%(72)$ \\
\hline 5 & Gentamycin & G & R & $50 \%(36)$ \\
\hline 6 & Nalidixic Acid & NA & I & $0 \%$ \\
\hline 7 & Doxycycline & Dox & R & $13 \%(10)$ \\
\hline
\end{tabular}

$\mathrm{S}=$ sensitive $\quad, \mathrm{R}=$ resistant $\quad, \mathrm{I}=$ intermediate resistant

\section{Discussion}

Antibiotic sensitivity testing is an essential tool for treatment. $P$. aeruginosa is considered as one of urinary tract infection and is resistant to a range of antibiotics due to the permeability barrier provided by its outer membrane for hydrophilic substances $^{14}$, although using sometimes surfactant as a permeabilizing agent to enhance the interaction of hydrophilic material with the hydrophobic cell wall did not enhance the antibacterial activity of some agent against $P$. aeruginos $a^{15}$.In the present study the in vitro antibiotic sensitivity test of isolated $P$. aeruginosa strains examined reveled Amikacin to be the most effective antibiotic followed by Norfloxacin , Ciprofloxacin \& Tobramycin in decreasing order. It is found that most of the investigated $P$. aeruginosa strains have noticeable resistance to Doxycycline.
Malla et $a l^{16}$ reported that $P$. aeruginosa were susceptible $100 \%$ to Amikacin and Gentamycin but $(80-100 \%)$ resistant to Ampicillin. Prinsloo et $a l^{17}$ reported that $P$. aeruginosa were susceptible to Cefepime in combination with Amikacin. These findings indicated that the antimicrobial sensitivities of the bacteria isolated from persons with UTI are variable ; therefore, antimicrobial agents should be selected on the basis of bacterial culture and sensitivity tests. The susceptibility of $P$. aeruginosa to Amikacin indicating that Amikacin is clinical choice to treat invasive $P$. aeruginosa then Norfloxacin , Ciprofloxacin \& Tobramycin which lead to say that aminoglycoside like Amikacin and fluoroquinolones such as Ciprofloxacin are usually effective against $P$. aeruginos $a^{18}$.In conclusion, isolation and identification of microbial agents responsible for UTI is a 
fundamental point for the diagnosis of the process and the initiation of a correct treatment. Therefore, antimicrobial susceptibility tests should be performed, especially in cases in which multiresistant bacteria are suspected. The present study indicates that Amikacin, Norfloxacin , Ciprofloxacin \& Tobramycin could be the most effective agents for the treatment of UTI caused by $P$. aeruginosa.

\section{References}

1.Kiss, G. ; Radvanyi , S. \& Szigeti , G.: New combination for the therapy of canine otitis externa. I. Microbiology of otitis externa. J. Small Anim. Pract. , 1997;38: 51 $-56$.

2.Todar , Kenneth : Todar's Online Textbook of Bacteriology. " The Good , the Bad, and the Deadly " . ( SCIENCE Magazine - June 4, 2004 - Vol 304 : p 1421.

3.Vianelli , N. ; Giannini , M.B. \& Quartic , C. : Resolution of a Pseudomonas aeruginosa outbreak in a haematology unit with the use of disposable sterile water filter. Haematol J. 2006 ; 91 (7) : 983 - 985.

4.Orenstein, R. and Wong, E. S.: Urinary tract infections in adults. American Family Physician; 1999 .www. aafp.org /afp/99031ap /1225.html.

5.Mohammed , H. K. : Urinary tract infection in patients hospitalized at $\mathrm{Al}$ - Rasheed military hospital. M Sc. Thesis in Microbiology. College of Medicine. Baghdad University ; 1989.

6.Price , L.B. ; Johnson, E. ; Vailes , R. \& Silbergeld, E. : Fluoroquinolone - resistant Campylobacter isolated from conventional and antibiotic - free chicken products. Environ. Hlth. Perspect. , 2005 ; 113: $557-560$.

7.Acar, J.F. \& Rostel , B. : Antimicrobial resistance : an overview. Rev. sci. tech. Off. Int. Epiz. , 2001 ; 20(3): $797-810$.

8.Osterblad , M. ; Hakanen , A. ; Manninen , R. ; Leistevuo , T. ; Peltonen , R.; Meurman , O.; Huovinen, P. \& Kotilainen, P. : A comparison of antimicrobial resistance in enterobacteria in fecal flora. Antimicrob. Agents Chemother. , $2000 ; 44$ (6) : 1479 -1484 .

9.Edwin , L. ; Dimatatac , M.D.; Marissa , M.; Alejandria , M.D.; Cecilia Montalban ; M.D. ; Cristina Pineda , R.M.T. ; Concepcion Ang, R.M.T. \& Rachel Delino , M.S. : Clinical Outcomes and Costs of Care of Antibiotic Resistant Pseudomonas aeruginosa infections. Phil. J. Microbiol. Infect. Dis.2003 ; 32 (4) : $159-167$.

10. Greta , G. ; Alvydas , P. \& Violeta , K. : The pecularities of Pseudomonas aeruginosa resistance to antibiotics and prevalence of serogroups. Medicina ( Kaunas ) 2007 ; 43 (1) $: 36-42$.

11. Reid, T. M. ; Duerden , B. I. ; Porter, I. A. and Turk, D. C. Ashort textbook of Medical Microbiology $.5^{\text {th }}$ ed. Hodder and Stoughton, London .1984.

12. Collee, J.G.; Fraser, A.G.; Marmion , B.P.\& Simmons , A. Mackie and Maccartney, practical Medical Microbiology. $14^{\text {th }}$ Ed. , the Churchill Living Stone Inc., USA. 1996.

13. Ligthner, D. V.. A Handbook of Shrimp Pathology and Diagnostic Procedures for Diseases of Cultural Penaeid Shrimp.section 4. World Aquaculture Society, Baton Rouge,Louisiana, USA.1996.

14. Yoshimura , F. and Nikaido, H.: Permeability of Pseudomonas aeruginosa outer membrane to hydrophilic solutes. J. Bacteriol.1982; 152 (2):636-642.

15. Karunathilake, A.A.K. ; Kumbukgolla ,W.W.; Ekanayake , E.W.M.A. ; 
Thevanesam ,V. ; Kumar, N.S.\& Bandara , B.M.R. Screening for antibiotic activity of tea catechins against Pseudomonas aeruginosa and Enterococci. Proceedings of the Peradeniya University Research Sessions, Sri Lanka. 2007;12(1):89-91.

16. Malla , K.K.; Sarma , M.S.; Malla, T.\& Thapalial ,A. Clinical profile, bacterial isolates and antibiotic susceptibility patterns in urinary tract infection in children hospital based study. J. Nepal Paediatr. Soc. 2008; 28(2):52-61.
17. Prinsloo , A. ;Van Straten , A.M.S. \& Weldhagen , G.F. Antibiotic synergy profiles of multi drug resistant $P$. aeruginosa in a nosocomial environment. South Afr. J. Epidemiol. Infect.2008; 23(3): 7-9.

18. Shigeharu et al . In vitro effects of combinations of antipseudomonal agents against seven strains of multidrug - resistant $P$. aeruginosa. Journal of Antimicrobial Chemotherapy. 2003; 52(6):911-914.

\section{حساسية بكتريا Pseudomonas aeruginosa المعزولة من الإدرار لبعض البطإ

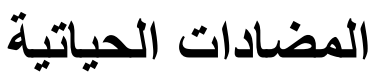

$$
\text { هدى علي صالح ملية الصبيدلة / جبد البارية الكوفة علي سليم عبد الرضا }
$$

\section{الخلاصة}

تعد بكتريا Pseudomonas aeruginosa احد أنواع جنسمونة Pseudomonas إذ إنها عصيات سالبة لصبغة كرام

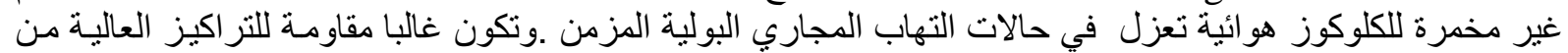

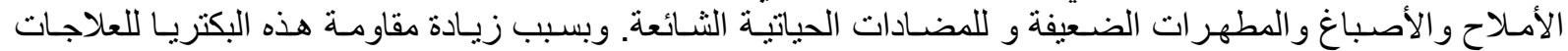

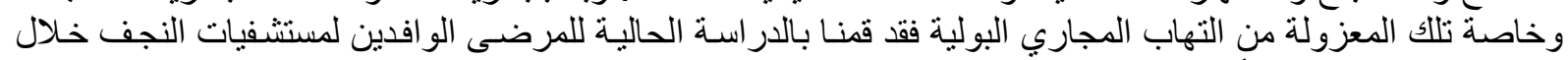

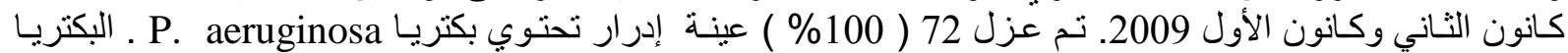

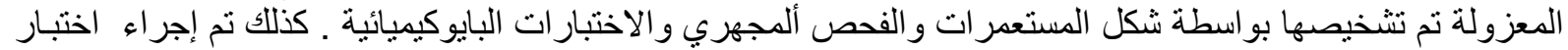

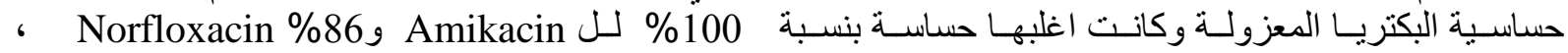
Doxycycline ومقاومة بنسبة عالية لل Doxycycline 